\title{
Where are they Now? Analyses of Alumnae Data
}

\section{Dr. Andrea L Welker, Villanova University}

Dr. Andrea L. Welker, PE, is a professor in the department of Civil and Environmental Engineering at Villanova University. Dr. Welker teaches a variety of geotechnical undergraduate and graduate classes, including soil mechanics, foundation design, geoenvironmental engineering, and geosynthetics. Her research focuses on the geotechnical aspects of stormwater control measures and the use of recycled materials in plastic pipes. In addition to teaching and performing research, she is the assessment chair and study abroad advisor for her department, the midterm director of the Civil Engineering Division for ASEE, and is the chair of the Continuing Education Committee for the Geo-Institute. 


\title{
Where are they Now? Analyses of Alumnae Data
}

\begin{abstract}
For more than two decades the percentage of women graduating nationally with a Bachelor of Science in Civil Engineering (BSCE) has been about 20\% to 25\% and the percentage of women practicing as engineers has been about $11 \%$. Studies conducted by the Society of Women Engineers and the National Science Foundation revealed that nationwide women are more likely to leave the engineering profession than men. Workplace climate was a large factor in women's decision to either leave or never enter the profession after graduating from college. Previous research indicates that women that persist in engineering have developed a strong sense of engineering identity and have developed skills to navigate the workplace environment. At Villanova University, the number of women graduating with a Bachelor of Science in Civil Engineering has been 33\% over the past three years and the percentage of women faculty is nearly 50\%, which are both above the national average. This paper explores whether the women graduates of this department persist in the profession at higher percentages than what has been found nationally and if their persistence in the profession is comparable to the men who graduate from the program. In other words: does an undergraduate program that is successful at recruiting women translate to higher persistence in the profession? Alumni surveys conducted by the department were utilized to examine women and men's persistence in engineering and the workforce and the attainment of additional degrees and credentials. In addition, the survey results were buttressed by interviews with alumnae to provide some personal insight into women's decisions to remain in engineering.
\end{abstract}

\section{Introduction}

For more than two decades the percentage of women earning a bachelor of science in engineering and the percentage of women practicing engineering has remained at approximately $20 \%$ and $11 \%$, respectively ${ }^{1}$. Women leave the profession of engineering at a much higher rate than men ${ }^{1,2}$. The Society of Women Engineers (SWE) ${ }^{3}$ reported that less than half of men leave engineering, while two thirds of women leave the profession. Fouad, et al. completed a longitudinal study that included surveying 5,562 women who graduated with a bachelor's degree in engineering ${ }^{1}$. The women that had obtained engineering degrees were sorted into three categories: those that did not pursue a career in engineering after graduation (10\% of the women surveyed), those that left the engineering profession (27\%), and those that stayed (60\%) (does not equal $100 \%$ because of rounding) ${ }^{1}$. Although the absolute percentages reported by SWE and Fouad, et al. are quite different; the relative percentages of women leaving the profession as compared to men was similar. Of those that never entered the profession, $80 \%$ were working in another field and 20\% had never planned to enter the profession and pursued a non-engineering graduate degree. The women surveyed cited the lack of flexibility, the culture, and the management of engineering firms as the reasons why they decided not to enter the profession. Of the women that left engineering, most were working in another field. About $20 \%$ that left indicated that it was because they did not "like the workplace climate, their boss, or the culture." About 11\% cited "working conditions, too much travel, lack of advancement, or low salary" as reasons why they left ${ }^{1}$. The reasons cited for leaving the profession by the women interviewed by Fouad, et al. were similar to those reported by previous research on the topic ${ }^{4}$. The only significant difference was that family obligations were cited as one of the primary reasons for 
leaving the profession by these other studies, whereas Fouad, et al found that only $8 \%$ of the women they surveyed left engineering to spend time with family ${ }^{1,4}$. Hunt found that women were more likely to leave engineering if they felt isolated by their gender; in other words the more male-dominated the workplace, the more likely they were to leave ${ }^{5}$.

Previous research has shown that women who persist in engineering strongly identify as engineers ${ }^{4}$. This is a necessary, but not sufficient characteristic of those that persist, as Fouad, et al. did not find any significant differences in interest, confidence, or identity between the women that left engineering and those that stayed ${ }^{1}$. In addition to strongly identifying as engineers, women must feel valued and recognized for their work, feel personal fulfillment in their work, and sense that they belong in the profession to persist in engineering ${ }^{1,2}$. In addition, the women that persist have found a way to navigate their way through challenging work environments ${ }^{2}$.

It was hypothesized by the author that women that graduated from an undergraduate program that has shown strength in recruiting and retaining women should persist in the engineering field in greater numbers. This program provides service learning, study abroad, and mentoring opportunities, which were important to the women entering and graduating from the program ${ }^{6}$. Prior research has shown that women develop strong engineering identities and leadership skills as a result of service learning opportunities and leadership training ${ }^{7}$. Students that develop this identity indicate that they intend to persist in their engineering career ${ }^{8}$. Two alumni surveys that were department specific as well as interviews with selected alumnae will be used to elucidate this issue and create a narrative.

\section{Institutional Background}

Villanova University is a comprehensive Roman Catholic institution founded in 1842 by the friars of the Order of St. Augustine. The University welcomes students of all faiths and is located approximately 10 miles west of Philadelphia. The University offers a wide variety of degree programs through four colleges: the College of Liberal Arts and Sciences, the School of Business, the College of Engineering, and the College of Nursing. The College of Engineering offers BS and MS programs through its four departments: Civil and Environmental, Chemical, Electrical and Computer, and Mechanical. The College also offers a PhD. The university's Carnegie Classification is a Doctoral University with moderate research activity (R-3).

The university is described as “more selective” by US News and World Report". In the College of Engineering, the combined Scholastic Aptitude Test (SAT) for the $25^{\text {th }}$ to the $75^{\text {th }}$ percentile is typically 1850 to 2100 . Typically, 95\% of the students enrolling ranked in the top 25\% of their high school. Nearly all of the students enrolled within the program are considered "traditional" full-time students that enrolled in college immediately after graduating high school ${ }^{10}$.

\section{Recruiting and Retaining Women at the Undergraduate Level}

A recent analysis of the student and faculty population at Villanova University revealed that both the percentage of women students and faculty were higher than the national average ${ }^{6}$. These statistics are summarized in Table 1 . The results of the analysis of the program, which included an incoming student survey, focus group discussions, and a senior exit survey, indicated that the overall culture of the program was critical to women entering and successfully completing the 
engineering program. In addition, as found in other studies, recruiting women was important because the retention rate in the program was similar for men and women at about $90 \%{ }^{6}$.

Academic reputation and the positive employment prospects of obtaining a BSCE from Villanova University are of paramount importance to both men and women. This indicates that while other factors may provide "added value," the major focus of any program needs to be creating an academically robust degree program that provides students the knowledge, skills, and attitudes they need to succeed after graduation. The other factors of the program that were attractive to women considering the program were opportunities to increase their cultural awareness through service learning and study abroad; the normality of seeing women students and faculty; and a strong sense of community ${ }^{6}$.

Table 1. Percentages of Women Earning Bachelor's Degrees and Women Faculty ${ }^{6}$ (nationwide statistics from Yoder ${ }^{11}$ )

\begin{tabular}{|l|c|c|c|c|}
\hline \multirow{2}{*}{} & \multicolumn{2}{|c|}{ Engineering } & \multicolumn{2}{c|}{ Civil Engineering } \\
\cline { 2 - 5 } & Nationwide & $\begin{array}{c}\text { Villanova } \\
\text { University }\end{array}$ & Nationwide & $\begin{array}{c}\text { Villanova } \\
\text { University }\end{array}$ \\
\hline $\begin{array}{l}\text { \% of bachelor's degrees } \\
\text { awarded to women }\end{array}$ & 19.1 & 30.7 & 21.0 & 34.0 \\
\hline $\begin{array}{l}\text { \% of women tenured/tenure- } \\
\text { track faculty }\end{array}$ & 14.5 & 23.8 & 15.4 & 54.0 \\
\hline
\end{tabular}

\section{Civil and Environmental Engineering Alumni Survey Results}

The Civil and Environmental Engineering Department, through our Office of Planning and Institutional Research (OPIR), surveys its alumni every three years. The two most recent surveys, conducted in 2011 and 2014, were analyzed for this paper. The data collected were sorted by gender by OPIR. The graduating classes of 2000, 2003, 2005, 2007, 2008, 2009, 2010, and 2012 were represented in these two surveys. Most the questions from the two surveys were identical. The response rates by graduating year varied from a high of 45\% for the class of 2010 to a low of $28 \%$ for the class of 2000. In total, 136 graduates responded to these surveys; 44 of the respondents were women (32\%) and 92 (68\%) were men. The percentages of men and women responding was similar to the graduation percentages observed over the past few years.

Graduates were provided with a list of skills and asked to rate how important each skill was to perform the work in their profession. Choices were "not important," "important," and "very important." The percentage of women and men describing each skill as very important is shown in Figure 1. Functioning effectively as a team, communicating well orally, and acquiring new skills and knowledge on your own were viewed as very important by more than $80 \%$ of both men and women. There were only two skills that exhibited more than a 5 percentage point spread: understand professional and ethical responsibilities (women 7 percentage points more than men) and write effectively (women 11 percentage points more than men).

Alumni were then asked to rate to what extent Villanova University enhanced that skill. Choices were "not at all" to "greatly" on a scale of one to five (Figure 2). The average ratings for both men and women were nearly identical for all skills. 
Understand global/societal context of engineering Understand professional \& ethical responsibilities Identify moral \& ethical issues Use quantitative skills Function effectively as a member of a team

Acquire new skills \& knowledge on your own Use technology \& other modern engineering tools Communicate well orally Write effectively

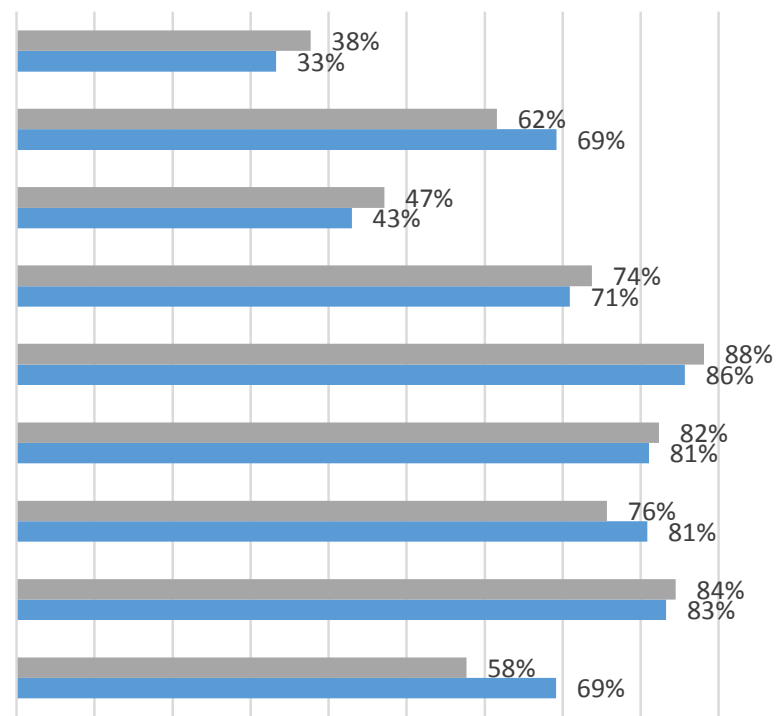
$\begin{array}{llllllllllll}0 \% & 10 \% & 20 \% & 30 \% & 40 \% & 50 \% & 60 \% & 70 \% & 80 \% & 90 \% & 100 \%\end{array}$

Figure 1. Percentage of women and men ranking a skill as very important to the work in their profession

\section{Men Women}

Understand global/societal context of engineering

Understand professional \& ethical responsibilities

Identify moral \& ethical issues

Use quantitative skills

Function effectively as a member of a team

Acquire new skills \& knowledge on your own

Use technology \& other modern engineering tools

Communicate well orally

Write effectively
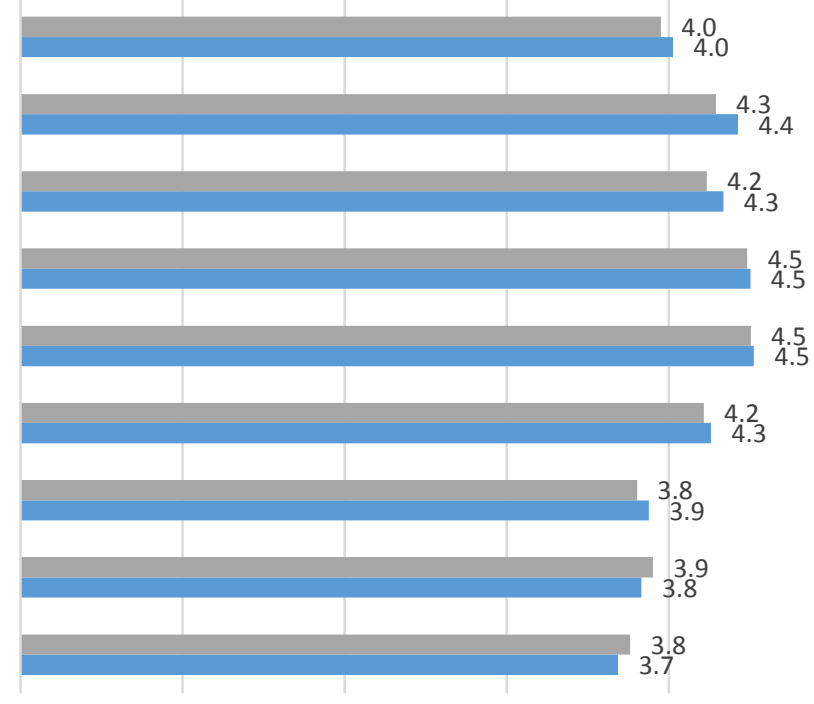

0

1

2

3

4

Figure 2. Average scores for women and men ranking how well Villanova University enhanced their skills 
Alumni were asked if they had obtained their license as a Professional Engineer, some other professional license, or if they had passed the Fundamentals of Engineering Exam. More women than men answered affirmatively to all three questions. At the time that the alumni participated in the surveys, approximately $45 \%$ of them would have been eligible to sit for the Professional Engineer's exam in the state of Pennsylvania.

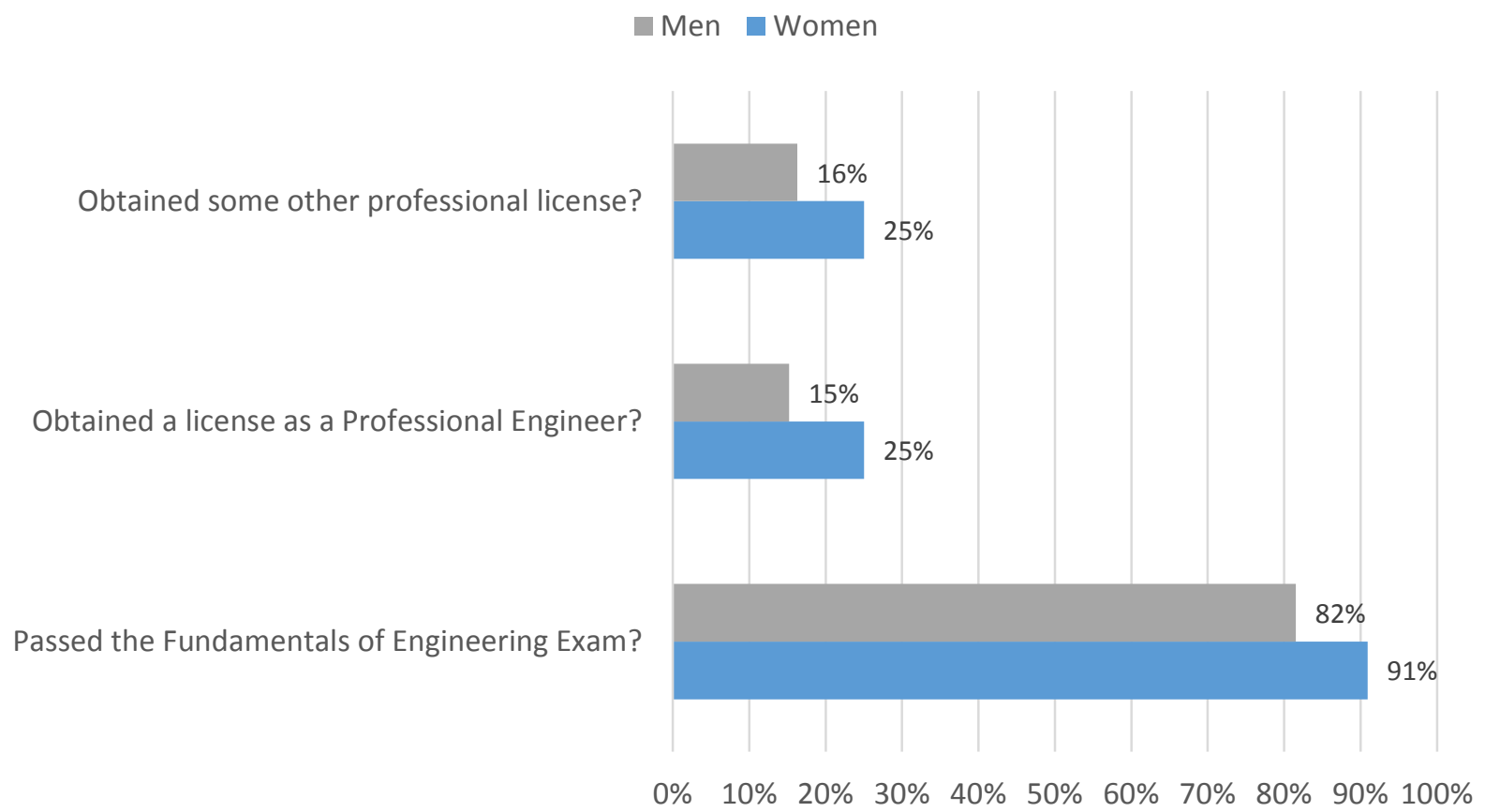

Figure 3. Percentage of women and men obtaining licenses or passing the Fundamentals of Engineering exam

Alumni were asked what their primary activity was in the year following graduation (Figure 4) and currently (Figure 5). In both cases, a higher percentage of women were employed full time and performing some other activity. In both cases, a higher percentage of men were in the military or pursuing graduate school full time. More women than men were performing volunteer service immediately after undergraduate, however, that switched when examining the current year. 


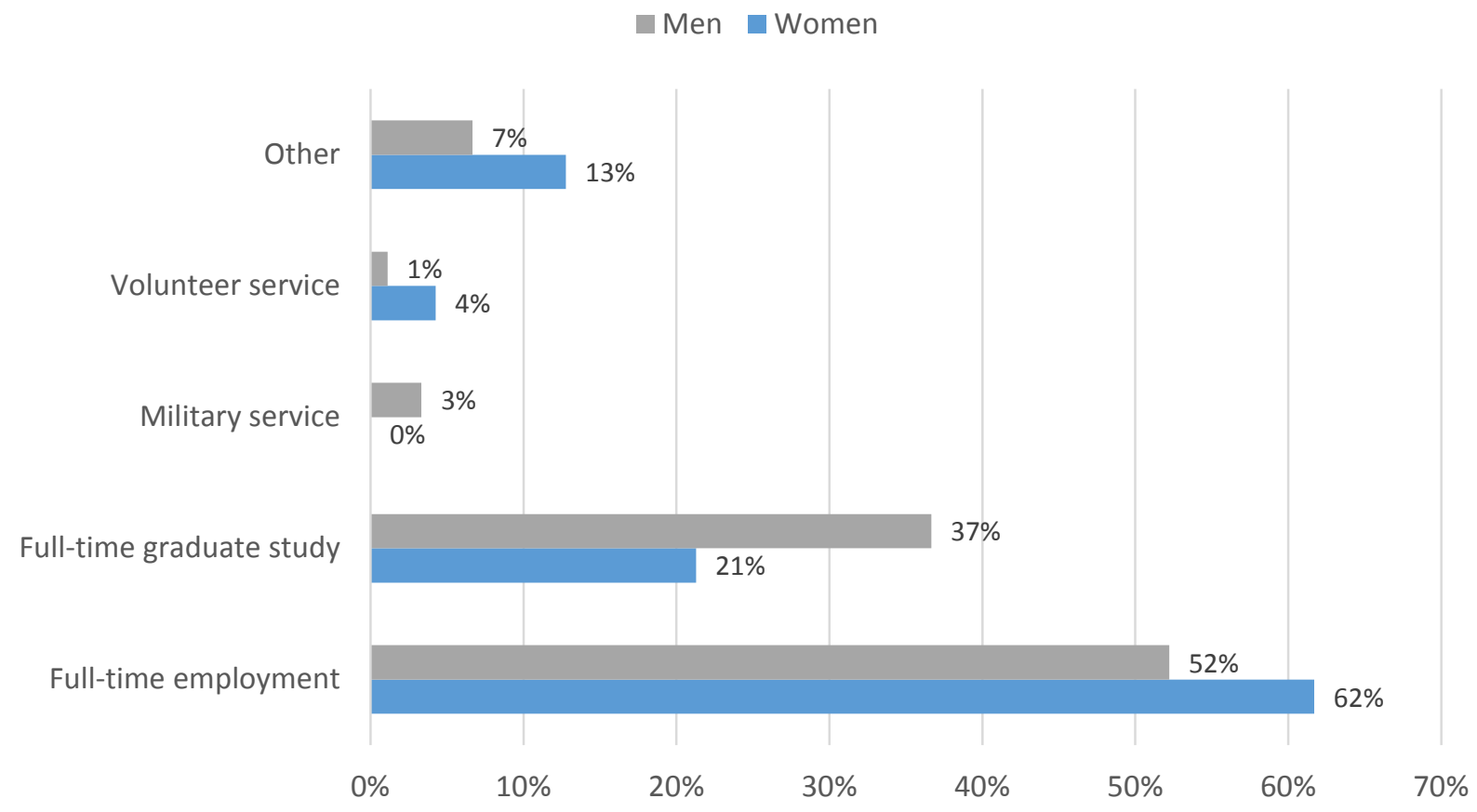

Figure 4. Primary activity the first year after graduation

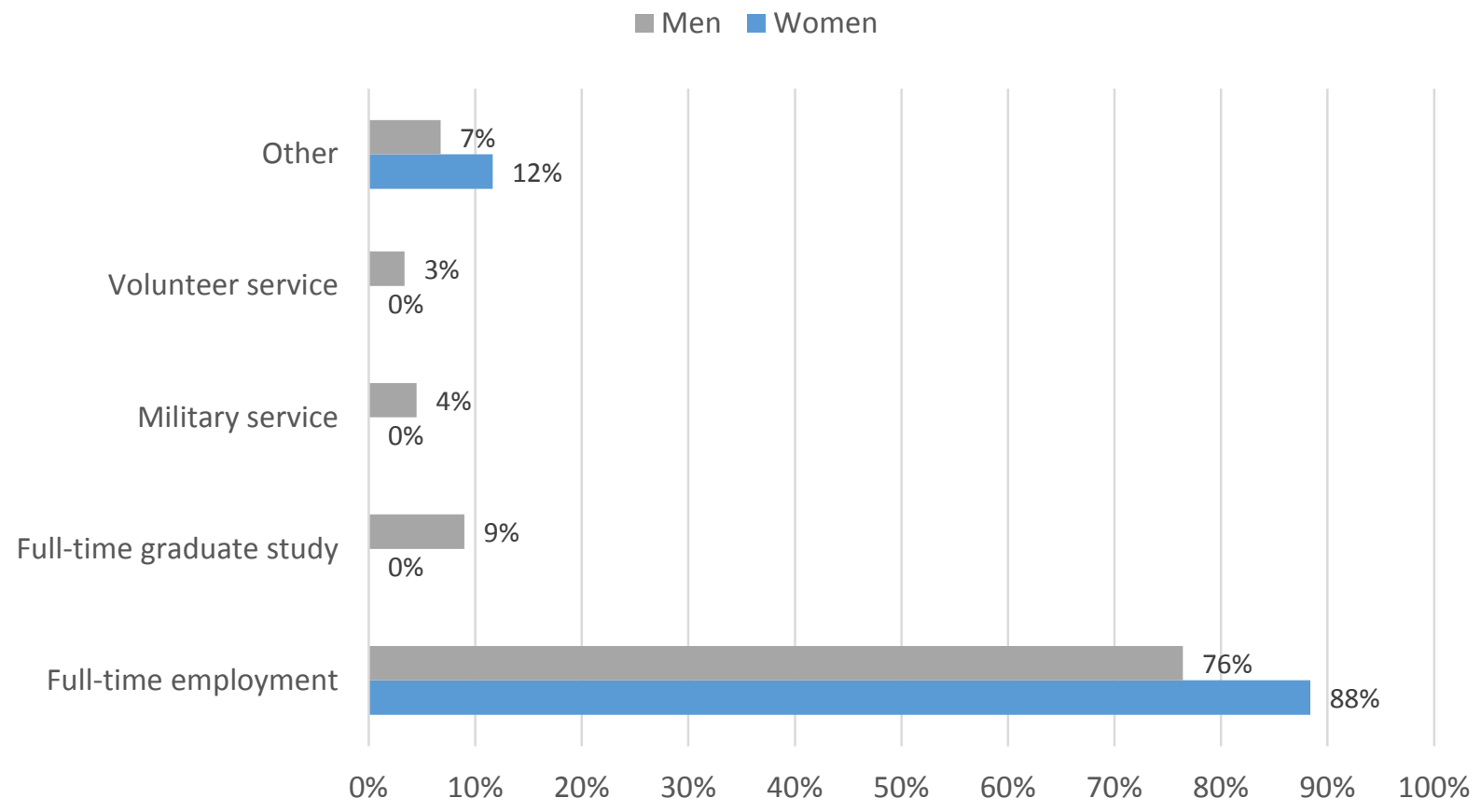

Figure 5. Primary activity in the current year

The alumni were asked about what field they were employed in or studying the first year after graduation (Figure 6) and in the current year (Figure 7). In both cases a higher percentage of women were employed or studying civil engineering. A higher percentage of men were working or studying another field of engineering or something different than engineering. A similar percentage of men and women were not employed or studying during the current year, although 
a higher percentage of men were not employed or studying the first year after graduation. There was not a significant shift in the percentages of women working within engineering from the first year after graduation to the current year, which is different than the trend found in the literature.

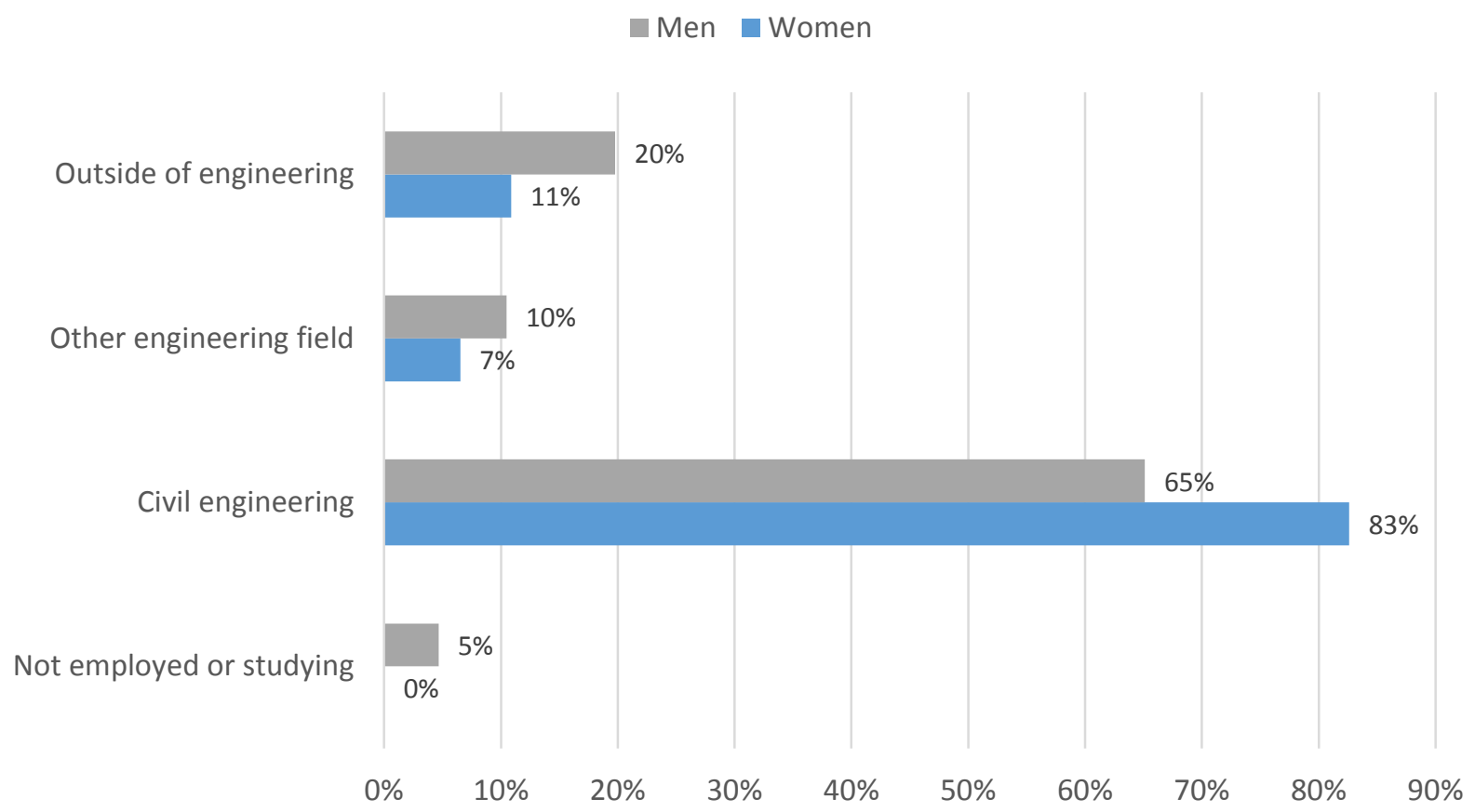

Figure 6. Field of employment or study the year after graduation

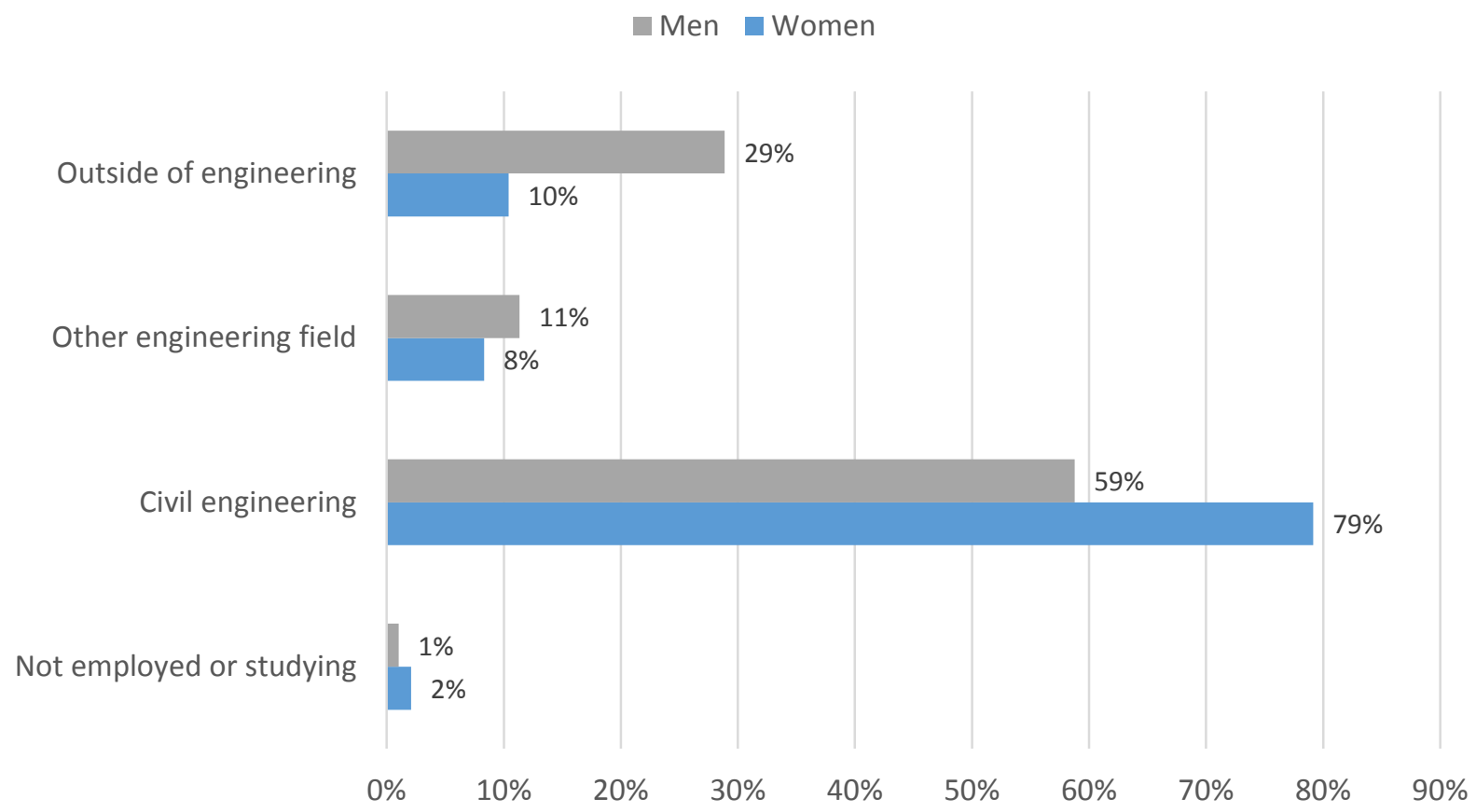

Figure 7. Field of employment or study in the current year 
The final question on the survey asked alumni to indicate any degrees they obtained since graduation or if they are currently enrolled in school (Figure 8). More men (4 percentage points in civil engineering and 7 percentage points in another field) than women had obtained a master's degree, while more women than men (7 percentage points) were currently enrolled in school, either full or part time.

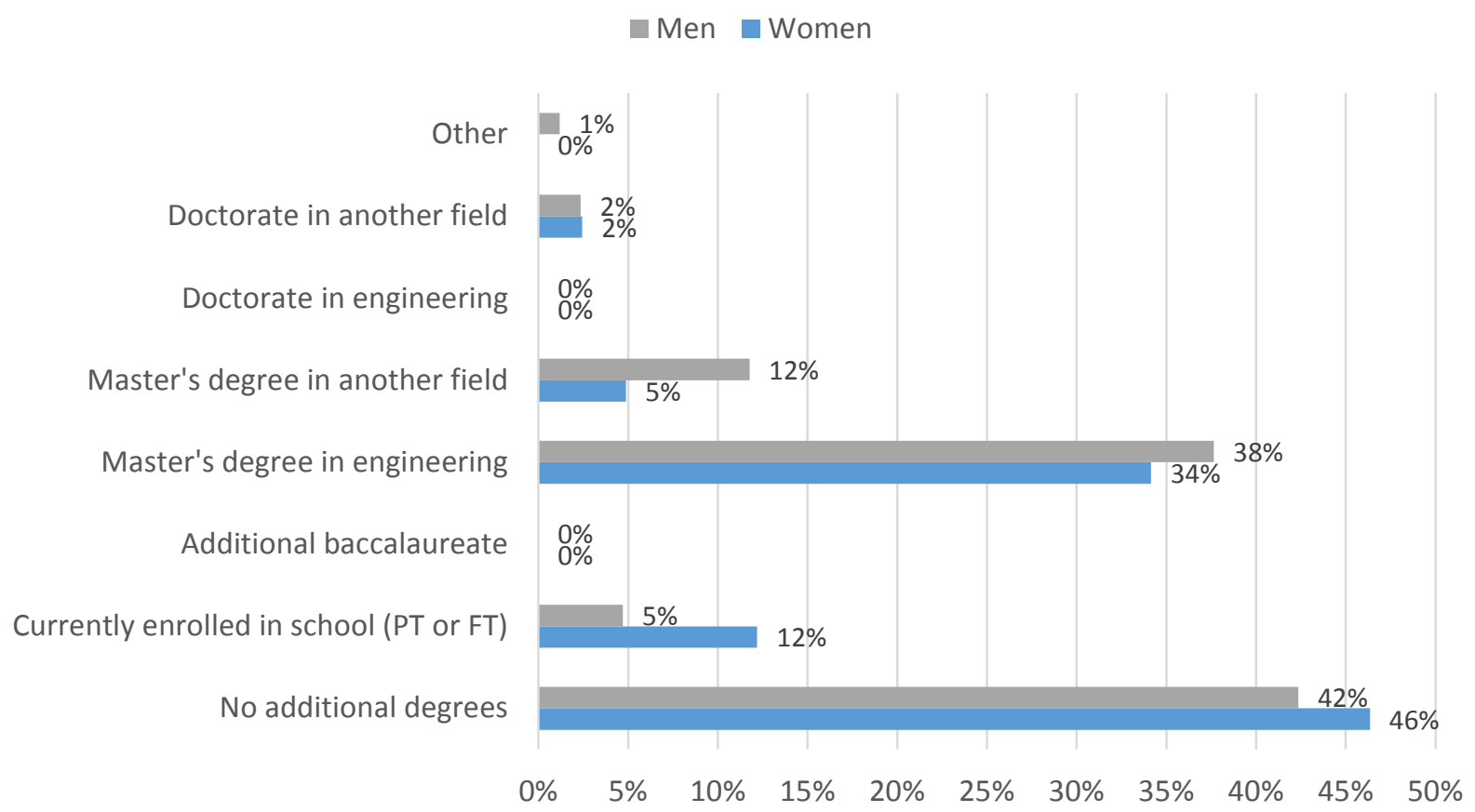

Figure 8. Degrees obtained since graduation

\section{Interviews}

Five female graduates from the classes of 1994, 1996, 2001, 2004, and 2006 who persisted in engineering were interviewed to provide some additional insight into the survey results. The four questions they were asked and a summary of their answers are summarized below.

1. Do you believe that Villanova University prepared you for your career?

All of the women interviewed believed that they were prepared for their career. One woman noted "the variety of course work touched on the technical skills necessary to be successful.” They described being recognized for their professionalism early their careers. The importance of communication as well as technical skills were described by several interviewees.

2. Did you feel prepared to navigate the field as a woman?

The women reported that this depended greatly on their work environment. Some work environments were very supportive and fair, while others were not. The older alumnae remarked that the engineering profession as a whole had become more "professional" and more accepting of women and that gender-related problems had lessened over time. They reported that learning strategies to handle gender bias during their undergraduate education would have been helpful. For example, one woman noted "I wish I had more 
exposure to and preparation for strategies to deal with gender bias in the workplace in my 20s." Some noted that this was important because they felt as though they were in a "bubble" during undergraduate.

3. Do you believe that you faced any additional hurdles because of your gender; e.g. promotions, work assignments, etc.?

The women noted that if their workplace valued communication skills, the ability to work in teams, and planning then they felt valued and expressed less frustration with their work environment. This is similar to the results reported by Ayre et al. ${ }^{2}$ Two alumnae noted that family issues were especially important to women. Finding ways to balance family and work life were concerning from both a perception and practical stand point.

Confidence to ask for what you need/want was also mentioned by several women. One alumna noted "as young women in a traditionally male populated industry, we should be taught to embrace our differences and uniqueness, and not try and conform and hide the fact that we are a minority.”

4. What advice would you have for young women beginning their careers in engineering? The importance of networking and building a strong and diverse network of professional mentors were mentioned by several women. In addition, several women noted that you should be confident and assertive, but not aggressive. In addition, you should set clear goals and find a mentor to help you achieve those goals. Furthermore, several noted that young women should not apologize for their life choices, but rather advocate for the acceptance of those choices. As one alumna stated "the field is not completely level, but improving all of the time.”

\section{Discussion and Conclusions}

The data indicate that women that graduate from Villanova University are persisting in engineering and obtaining additional credentials of licenses and degrees. The alumnae are lagging slightly in obtaining advanced degrees; however, the women are persisting in engineering and obtaining licenses at a higher percentage than men.

Fouad, et al. ${ }^{1}$ made several recommendations for universities and their curricula to increase the percentage of women that persist in engineering. These recommendations will be compared to Villanova University’s curricula to expose strengths and weaknesses.

The first recommendation was to "strengthen university-industry partnerships" to allow students to get an idea of workplace culture and provide for mentoring ${ }^{1}$. Most civil engineering students at Villanova University complete summer internships and all students interact with industry partners in several classes. Role-modeling is also discussed as part of this recommendation. The high percentage of women faculty at Villanova University provides these role models and mentoring opportunities ${ }^{6}$. Further efforts to link students with industry mentors would strengthen the program.

The second recommendation was to create climates that do not tolerate incivility ${ }^{1}$. Women in the program noted that they "felt comfortable and reassured" and noted that they felt "normal." 6 These statements indicate that the students are not subjected to incivility while pursuing their 
undergraduate degree. Furthermore, these statements are evidence that the students are

developing a strong engineering identity, which has been linked to career persistence ${ }^{4}$. However, some of the alumnae noted in the interviews that this civility did not always extend to the workplace and that strategies to handle these situation would have been useful.

The final recommendation was to "teach students career management skills."1 All alumni noted the importance of being able to work on a team and communicate effectively (Figure 1) and believe that Villanova University enhanced those skills (Figure 2). Leadership and service learning opportunities, which have been linked to recruiting and retaining women as well as providing women with the skills to navigate the workplace, are abundant at Villanova University $^{11}$. A new professional development program is being launched in the coming year that should help students learn career management skills.

In conclusion, the positive undergraduate experience provided by Villanova University provides women with the skills and confidence to persist in engineering at higher percentages than what is observed nationally after graduation. The use of alumni surveys to track the career paths of women and men could easily be replicated by other programs should they wish to pursue a similar analyses to determine how their alumnae's persistence compares to national data. In addition, an evaluation of Fouad, et al's ${ }^{1}$ recommendations in comparison with the curricular and co-curricular opportunities at a given school could be used to strengthen the undergraduate program.

\section{Acknowledgements}

The author would like to thank the Office of Planning and Institutional Research for sorting the alumni surveys by gender; the Department Chair, David Dinehart, and Dean of the College of Engineering, Gary Gabriele, for their support; and the women that agreed to be interviewed for this paper.

\section{References}

1. Fouad, N.A., Singh, R., Fitzpatrick, M.E., and Liu, J.P. (2012) Stemming the Tide: Why Women Leave Engineering, National Science Foundation, available at http://www.studyofwork.com/files/2011/03/NSF_Women-Full-Report-0314.pdf.

2. Ayre, M., Mills, J., and Gill, J. (2013). “’Yes, I do belong': the women who stay in engineering.” Engineering Studies, Vol. 5, No. 3, pp. 216-232.

3. Frehill, L. (2007). “The Society of Women Engineers (SWE) national survey about engineering: are women more or less likely than men to be retained in engineering after college?” SWE Magazine, Vol. 53, No. 4, pp. 22-25.

4. Plett, M., Hawkinson, C., VanAntwerp, J.J., Wilson, D, and Bruxvoort, C. (2011). “Engineering identity and the workplace persistence of women with engineering degrees." Proceedings of the 2011 ASEE Annual Conference and Exposition, Vancouver, BC, June 26-29.

5. Hunt, J. (2010). Why Do Women Leave Science and Engineering? Montreal: National Bureau of Economic Research. 
6. Welker, A., Nazar, K.L, and Bonfanti, P. (2015). "Recruiting and Retaining Women Engineers: An Analysis of a Successful College Program.” Proceedings of the 2015 ASEE Annual Conference and Exposition, Seattle, WA, June 14-17.

7. Wang, J., Patten, E., Shelby, R., Ansari, F., and Pruitt, L.A. (2012). "Leadership and service learning improves confidence of engineering skills in women." Proceedings of the 2012 ASEE Annual Conference and Exposition, San Antonio, TX, June 10-13.

8. Cech, E., Rubineau, B, Silbey, S, and Seron, C. (2011). "Professional role confidence and gendered persistence in engineering.” American Sociological Review, Vol. 76, No. 5, pp. 641-646.

9. US News and World Report (2014), available online at http://colleges.usnews.rankingsandreviews.com/best-colleges/villanova-3388, accessed 9 January 2015.

10. Horn, L. (1996) Nontraditional Undergraduates, Trends in Enrollment From 1986 to 1992 and Persistence and Attainment Among 1989-90 Beginning Postsecondary Students (NCES 97-578). U.S. Department of Education, NCES. Washington, DC: U.S. Government Printing Office.

11. Yoder, B. (2014) Engineering by the Numbers, available online at http://www.asee.org/papers-andpublications/publications/14_11-47.pdf, accessed 25 January 2016. 